\title{
Research on the Impact of the Novel Coronavirus Pneumonia Epidemic on the Price Fluctuation of the Pig Industry in My Country
}

\author{
Minqun Xu' ${ }^{1}$, Weiguang Pan², Binhong $\mathrm{Wu}^{3}$ \\ ${ }^{1}$ College of Economics and Management, Zhejiang Agriculture and Forestry University, Lin'an, China \\ ${ }^{2}$ Research Academy for Rural Revitalization of Zhejiang Province, Zhejiang Agriculture and Forestry University, \\ Lin'an, China \\ ${ }^{3}$ Ruida Futures Research Institute, Xiamen, China \\ Email: 942675266@qq.com
}

How to cite this paper: Xu, M. Q., Pan, W. G., \& Wu, B. H. (2021). Research on the Impact of the Novel Coronavirus Pneumonia Epidemic on the Price Fluctuation of the Pig Industry in My Country. Open Journal of Business and Management, 9, 1932-1941.

https://doi.org/10.4236/ojbm.2021.94104

Received: May 27, 2021

Accepted: July 24, 2021

Published: July 27, 2021

Copyright ( 2021 by author(s) and Scientific Research Publishing Inc. This work is licensed under the Creative Commons Attribution International License (CC BY 4.0).

http://creativecommons.org/licenses/by/4.0/

\section{(c) (i) Open Access}

\begin{abstract}
In order to effectively respond to the impact of the COVID-19 on the China's pig industry, by analyzing the impact of t the COVID-19 on the China's pig industry, three indicators were established from three aspects: upstream production link, midstream circulation link, and downstream consumption link. The degree of response to the COVID-19, in order to consider how to steadily promote the high-quality development of the China's pig industry in the context of the COVID-19. Construct a new COVID-19 situation public opinion index, use this index as a proxy variable for pneumonia epidemic situation, build a VAR model based on the daily data of the upstream, middle and downstream prices of the pig industry from January 19, 2020 to April 19, 2020, and conduct an empirical analysis. The COVID-19 has caused small fluctuations in product prices at different links in the pig industry chain, but the price fluctuations of each link are different. The price fluctuations of downstream consumer links are the largest. As the epidemic gradually controls, the impact on each link gradually weakens. In the face of the impact of the epidemic, China's economy still has great resilience. The overall impact of the pneumonia epidemic on China's pig industry is not large, and it does not change the fundamentals of China's economy. And put forward suggestions on strengthening the prevention and control of epidemic diseases, industrial support, and logistics system construction in view of the problems in each link of the pig industry chain under the epidemic situation.
\end{abstract}

\section{Keywords}

COVID-19, Public Opinion Index, Pig Industry Chain, VAR Model, Price Fluctuation 


\section{Introduction}

Since December 2019, the new coronavirus pneumonia epidemic has raged across the country and the national economy has been severely damaged. The situation of the epidemic continues to deteriorate, causing violent turbulence in many industries in China. At present, affected by the African swine fever, my country's pig industry is still full of severe challenges. Studying how the pneumonia epidemic affects the price level fluctuations and price response differences of all production links in the pig industry chain is to ensure that consumers' actual consumption levels. Important measures to reduce the impact of the pneumonia epidemic on the national economy and speed up the economic recovery in the context of the epidemic are of great significance. In recent months, scholars have focused on the identification, clinical characteristics, and vaccine research of the pneumonia epidemic. There is little research on the impact of the pneumonia epidemic on China's industrial economy. Li Jun analyzed the difficulties faced by all aspects of the mutton sheep industry, and concluded that the pneumonia epidemic will have little impact on the mutton sheep industry in the short term, but will have an adverse impact on all aspects of production in the medium term: the increase in sheep feed and the closure of small and medium-sized sheep enterprises may lead to the long-term Opportunities such as corporate transformation and upgrading appear (Li \& Jin, 2020). So far, the domestic pneumonia epidemic has had less impact and impact on the livestock industry.

In this regard, this article draws on the existing research on the transmission mechanism of industrial prices from emergencies, and $\mathrm{Yu}$ et al. (2009) uses quantitative model analysis to find that the avian influenza epidemic has a significant impact on the income of farmers in the short term (Yu et al., 2009), and Zhang \& Zhang (2011) uses structural vector regression model to analyze The transmission effect of emergencies on the price of the broiler industry, and it is concluded that emergencies have a significant impact on the price level (Zhang \& Zhang, 2011). Wu et al. (2019) analyzed the relationship between the epidemic and the price of live pigs by establishing a live pig epidemic width index ( $\mathrm{Wu}$, Wang, \& Lang, 2019). Different research methods have been adopted to study the mechanism of market impact by emergencies, but none of them have achieved scientific quantification of emergencies, thus ignoring the problem of different impacts of emergencies on the market at different time points with different severity. To solve this problem, domestic scholars such as Ding et al. (2019) established avian influenza public opinion index and used the MS-VAR model to analyze the market status of the broiler industry at different time points under the background of avian influenza (Ding, Zheng, \& Xiao, 2019). Considering that the pneumonia epidemic has brought severe challenges to China's economic development, such as economic expected decline, financial market turmoil, and the impact of the real economy. However, domestic scholars have few empirical studies on the impact of the pneumonia epidemic shortly after the outbreak on economic fluctuations. The research methods that use scientific 
quantification of sudden events are mostly concentrated in other animal husbandry industries, and there are few studies on the pig industry. Therefore, based on the above research ideas of scholars, this article uses the search engine Baidu to construct a new coronavirus pneumonia epidemic public opinion index and use it as an independent variable. Through constructing a vector autoregressive model, this article explores the impact of the pneumonia epidemic on different production links in the pig industry chain. It hopes to provide a scientific basis for the government's policy choices on how to promote the high-quality development of the pig industry in my country under the background of the pneumonia epidemic.

\section{Data Source and Model Construction}

\subsection{Construction and Acquisition of Public Opinion Index}

The epidemic public opinion index (Xu \& Gao, 2017) is a quantitative time-series indicator of the public's attention to the pneumonia epidemic based on Internet big data, which can comprehensively reflect the extent of the new coronavirus pneumonia epidemic. With the help of the Baidu Index platform, the search volume of "new coronavirus pneumonia" is used as the data basis, and the mouse is used to intercept the data on the trend curve and perform data statistics (Sui \& Geng, 2019). For research needs, the data are all logarithmic. Figure 1 is the trend chart of the public opinion index of the pneumonia epidemic. From Figure 1 , it can be seen that there are three peak searches for "new coronavirus pneumonia" in a short period of time, the first time was on January 30, 2020, the world health organization announced that will be coronavirus disease as a public health emergency of international concern, the second was on February 6, 2020, zone spreading mechanism press conference held by the State Council "a province bag one city" support of hubei, and the third time was on February 8, 2020, wuhan thor mountain one hundred million yuan consign is used, The COVID-19 patients were hospitalized in a concentrated way. These periods were the peak of COVID-19 outbreak.

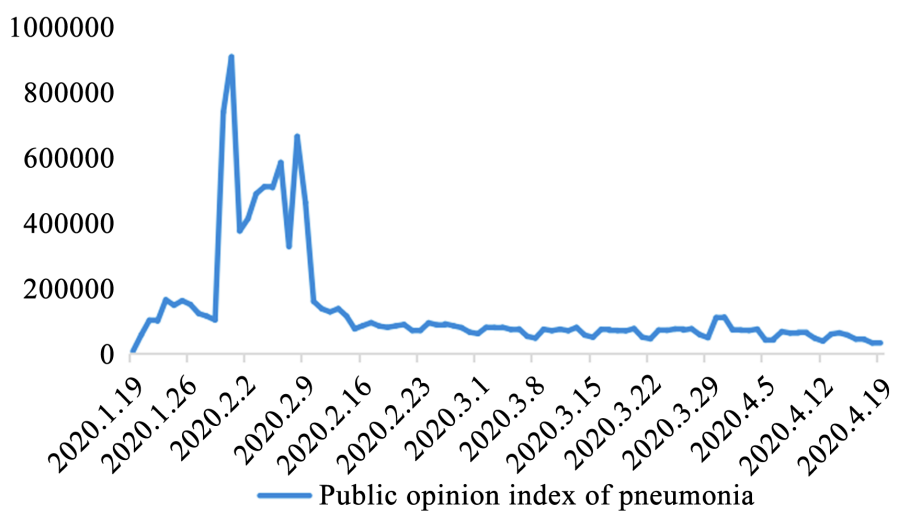

Figure 1. The trend chart of the public opinion index of the pneumonia epidemic. Source: Baidu Index (https://index.baidu.com/v2/index.html\#/). 


\subsection{The Market Price Acquisition and Processing of the Pig Industry}

According to the characteristics of the pig industry, this article selects the corn price $\mathrm{X} 1$ in the upstream link, the internal three-yuan pig price $\mathrm{X} 2$ in the midstream link, and the wholesale pork price X3 in the downstream link. Logarithm processing is performed on the three, and the data interval is January 19, 2020. As of April 19, 2020, the above data are from China Pig.

\subsection{Model Construction}

Since the change of the natural logarithm of data does not change the original co-integration relationship, and can eliminate the heteroscedasticity in the time series and reduce the data fluctuation, the natural logarithm processing is carried out on the original data. In this paper, each variable is recorded as the new coronavirus pneumonia epidemic public opinion index $(\ln Y)$, the corn price in the upstream link $(\ln \mathrm{X} 1)$, the ternary live pig price in the midstream link $(\ln \mathrm{X} 2)$, and the wholesale pork price in the downstream link (lnX3). By constructing a VAR model to study the impact of the novel coronavirus pneumonia epidemic on the price fluctuations of the pig industry in my country, all operations of the model in this article are implemented under EViews10.0.

\section{Empirical Test}

\subsection{Unit Root Test}

In order to judge the stationarity of the data, the unit root test was performed on the time series, and the results are shown in Table 1.

\subsection{Johansen Cointegration Test}

In this paper, Johansen test is used for co-integration test. It can be seen that: the first-order difference time series all reject the null hypothesis, and there are 4 co-integration relations. The results are shown in Table 2.

Table 1. Unit root test.

\begin{tabular}{ccccc}
\hline Variable & Test type & ADF statistics & Critical value & Conclusion \\
\hline $\ln y$ & $(\mathrm{c}, \mathrm{t}, 2)$ & -3.353143 & -3.461094 & unstable \\
$\ln \mathrm{X} 1$ & $(\mathrm{c}, \mathrm{t}, 1)$ & -1.910562 & -3.460516 & unstable \\
$\ln \mathrm{X} 2$ & $(\mathrm{c}, \mathrm{t}, 1)$ & -1.545540 & -3.460516 & unstable \\
$\ln \mathrm{X} 3$ & $(\mathrm{c}, \mathrm{t}, 2)$ & -2.854330 & -3.461094 & unstable \\
$\mathrm{d} \ln y$ & $(\mathrm{c}, \mathrm{t}, 1)$ & -9.784205 & -3.461094 & stable \\
$\mathrm{d} \ln \mathrm{X} 1$ & $(\mathrm{c}, \mathrm{t}, 0)$ & -16.48982 & -3.460516 & stable \\
$\mathrm{d} \ln \mathrm{X} 2$ & $(\mathrm{c}, \mathrm{t}, 0)$ & -12.50153 & -3.460516 & stable \\
$\operatorname{dlnX} 3$ & $(\mathrm{c}, \mathrm{t}, 1)$ & -9.574411 & -3.461094 & stable \\
\hline
\end{tabular}


Table 2. Johansen cointegration test.

\begin{tabular}{|c|c|c|c|c|}
\hline \multicolumn{2}{|c|}{ Hypothesized } & \multirow{2}{*}{ Statistic } & \multirow{2}{*}{$\begin{array}{c}\text { Trace } \\
\text { Critical Value }\end{array}$} & \multirow{2}{*}{$\begin{array}{c}0.05 \\
\text { Prob }^{\star *}\end{array}$} \\
\hline NO. of CE (s) & Eigenvalue & & & \\
\hline None* & $(c, t, 1)$ & -1.910562 & -3.460516 & unstable \\
\hline At most 1 & $(c, t, 1)$ & -1.545540 & -3.460516 & unstable \\
\hline At most 2 & $(c, t, 2)$ & -2.854330 & -3.461094 & unstable \\
\hline At most 3 & $(c, t, 1)$ & -9.784205 & -3.461094 & stable \\
\hline NO. of CE (s) & $(c, t, 0)$ & -16.48982 & -3.460516 & stable \\
\hline
\end{tabular}

**indicates that the coefficient is significant at the significance level of $5 \%$.

\subsection{Determination of Lag Order}

Through the above analysis, a VAR model can be established. The AIC and SC criteria are used to determine the optimal lag order. According to the minimization principle of information criterion, the parameter values of different lag orders are compared. The results are shown in Table 3: the optimal lag order is 2nd order.

\subsection{Estimation of VAR Model}

Use EViews10.0 software to establish a VAR model, and select the second-order lag interval. The result is shown in Figure 2: All unit roots fall within the unit circle.

\subsection{Impulse Response Analysis}

In this paper, the 10-period impulse response function is established on the above basis, and the result is shown in Figure 3.

Judging from the response of $\mathrm{d} \ln \mathrm{X} 1$ (corn price) to the new coronavirus pneumonia epidemic public opinion index (dlny): When the pneumonia epidemic public opinion index was positively impacted by one unit standard deviation in this issue, dlnX1 (corn price) was in the first to the first period. Phase 2 showed a negative response, and the response degree showed a decreasing trend, with the response degree being -0.000746 and -0.000426 respectively. After the 6th period, the response level approaches zero. This mainly shows that the occurrence of the pneumonia epidemic has caused changes in the price of corn, the raw material in the upper and middle links of the pig industry chain, in the short term, but as the epidemic is gradually controlled, the impact has gradually weakened.

Judging from the response of $\mathrm{d} \ln \mathrm{X} 2$ (internal ternary pig price) to the new coronavirus pneumonia epidemic public opinion index (dlny): When the pneumonia epidemic public opinion index is positively charged by one unit standard deviation in this issue, dlnX2 (internal ternary pig price) There was a negative response from period 1 to period 2 . The third period showed the greatest degree of positive response, which was 0.000440 . After the 5th period, the response degree approaches zero. This mainly shows that the impact of the pneumonia 


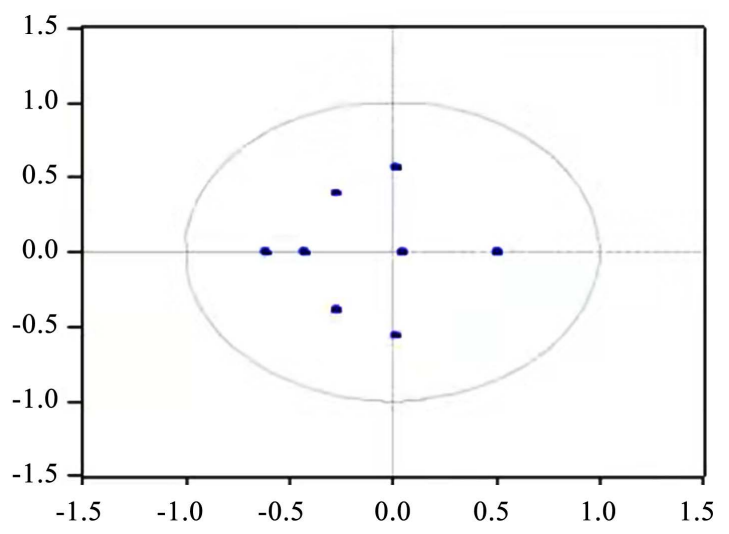

Figure 2. Inverse root of characteristic polynomial of VAR model.
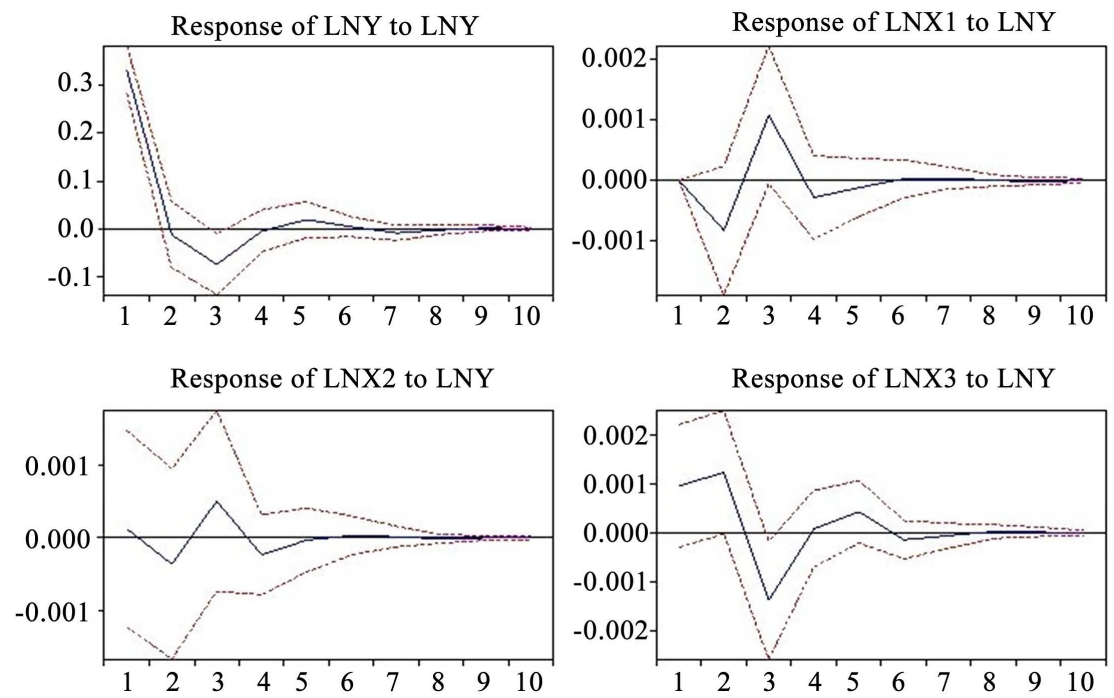

Figure 3. Results of impulse response function.

Table 3. Lag order selection table.

\begin{tabular}{ccccccc}
\hline Lag & LogL & LR & FPE & AIC & SC & HQ \\
\hline 1 & 906.2399 & NA & $5.67 \mathrm{e}-15$ & -21.45156 & -20.98528 & -21.26424 \\
2 & 927.7020 & $38.78697^{\star}$ & $4.99 \mathrm{e}-15^{*}$ & -21.58318 & -20.65062 & -21.20853 \\
\hline
\end{tabular}

${ }^{*}$ indicates that the coefficient is significant at the significance level of $10 \%$.

epidemic on the price of domestic ternary pigs is roughly the same as that on the price of corn in the upstream production link.

Judging from the response of $\operatorname{dln} \mathrm{X} 3$ (pork wholesale price) to the new coronavirus pneumonia epidemic public opinion index (dlny): after a positive impact of one unit standard deviation on the pneumonia epidemic public opinion index in this period, $\mathrm{d} \ln \mathrm{X} 3$ (pork wholesale price) was in the first period. By the second period, it showed the largest positive response, with a response degree of 0.000958. The 4th to 5th period showed a positive response, and the response degree showed an increasing trend. After the 6th period, the response degree 
tended to zero. This mainly shows that compared with the upper and middle stages of the pig industry, the pneumonia epidemic has the greatest impact on pork prices in the downstream consumption links. This can also be explained from another aspect: the production cycle of live pigs is long, the price adjustment cycle of the upper and middle links is longer, and the price adjustment of downstream consumption links is rapid. That is, short-term emergencies have a greater impact on the downstream consumption links of the industry, but have less impact on the upper and middle links of the pig industry.

\subsection{Variance Analysis}

It can be seen from Figure 4 that the new coronavirus pneumonia epidemic public opinion index (dlny) has shown a slight increase in the price fluctuations of the upstream (dlnX1) link of the pig industry from the first period to the fifth period, and the fifth period has shown a stable contribution rate, $2.76 \%$. The contribution rate of the epidemic public opinion index (dlny) to the fluctuations in the price of three yuan pigs in the midstream of the pig industry has shown an increasing trend from the first to the fourth period, and the fifth period has shown a stable contribution rate of $5.4 \%$. The epidemic public opinion index (dlny) has a stable contribution rate of $4.5 \%$ to the pork price in the downstream circulation links of the pig industry after the fifth period. Combined with the previous impulse response function, it can be seen that the pneumonia epidemic will have a certain impact on the pig industry in the short term, but the overall impact is not large.

\section{Conclusion and Recommendations}

\subsection{Conclusion}

The response of corn prices in the upstream production link to the public
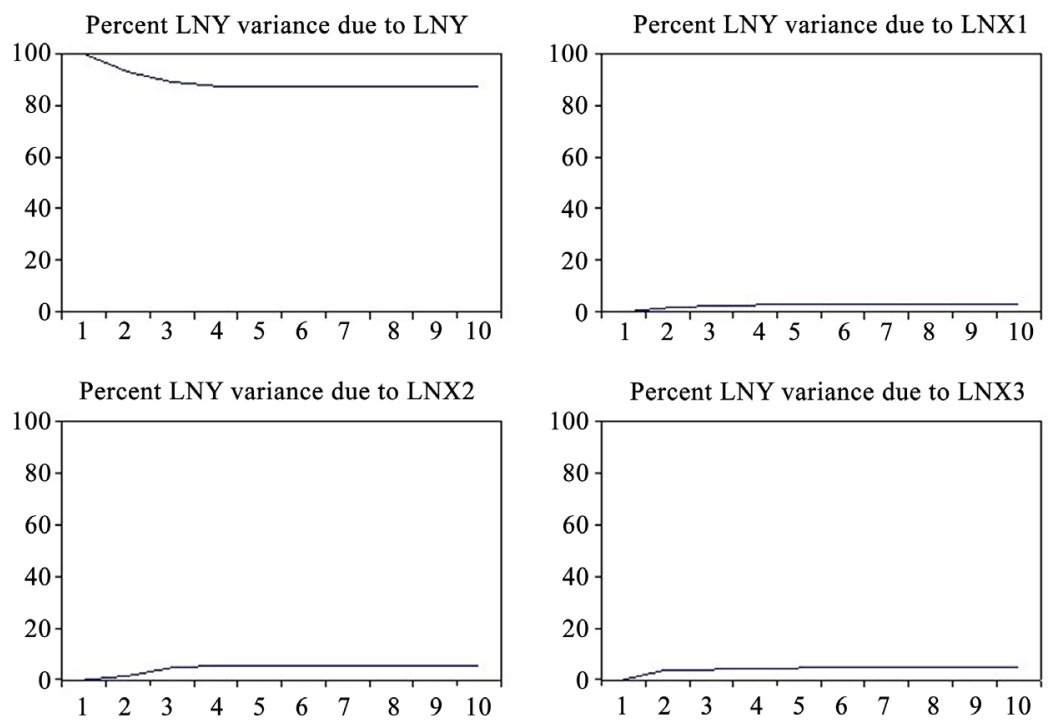

Figure 4. ANOVA results. 
opinion index of the pneumonia epidemic is less than that in the downstream consumption link. The results of the analysis of variance show that the public opinion index of the pneumonia epidemic has a stable contribution rate of $2.76 \%$ after the fifth period. This mainly shows that the outbreak of the pneumonia epidemic has caused a certain impact on upstream raw materials. The prevention measures such as roadblocks and lockdowns in rural areas have caused problems such as restricted transportation of raw material corn. On the other hand, it can be seen that the raw material corn inventory and temporary storage corn the relatively abundant supply played an important role and effectively resisted the impact of the pneumonia epidemic.

The price of domestic three-yuan pigs in the midstream circulation link has a small response to the pneumonia epidemic public opinion index, but it shows the largest positive response in the third period. The results of the analysis of variance show that the pneumonia epidemic public opinion index has a stable contribution rate after the sixth period. The contribution rate is $5.4 \%$. This shows that the impact of the pneumonia epidemic at this time has made the problem of the processing, circulation and transportation of goods blocked, especially during the epidemic prevention period in the slaughter, meat product processing, and cargo transportation of the pig circulation.

The average price of pork in the downstream consumption link has the greatest response to the public opinion index of the pneumonia epidemic, indicating that the sudden pneumonia epidemic has the greatest impact on the downstream consumption link of the pig industry, and the impact lasts the longest. The fifth period of downstream consumption will show a stable contribution rate, with a contribution rate of $4.5 \%$. The downstream consumption link is the main impact point of the pneumonia epidemic on the live pig industry chain, mainly due to the suspension of slaughterhouses, pork sales difficulties, and the decline in pork consumption during the epidemic. Therefore, the government's policy choices in the context of the pneumonia epidemic should attach great importance to downstream consumption links.

On the whole, the epidemic has little impact on my country's pig industry. This shows that my country, as the world's second largest economy, has great flexibility and resilience in the face of the impact of the epidemic. My country's economy can return to normal operation in a short period of time. The epidemic will not change the fundamentals of my country's economy.

\subsection{Recommendations}

For the upstream production links, one is to focus on strengthening the prevention and control of pig epidemics. Based on the above research, it can be clearly seen that emergencies will have a certain impact on the economy. The occurrence of African swine fever in my country in 2018 has caused a significant decline in the stock and slaughter of live pigs in the past two years. The elasticity of pork supply has become significantly greater, and the market has insufficient 
supply and high prices. This has caused extreme problems for consumers and producers. The second is to focus on strengthening industrial support policies. The government should adopt expansionary policies such as reducing taxes on farmers' income, provide certain welfare subsidies to pig farmers, speed up the resumption of work and production of the pig industry, and realize the restoration of pig production capacity. The third is to focus on strengthening scientific farming, instead of blindly pursuing large-scale farming, but adopting a moderately large-scale farming plan to achieve management integration and accelerate the transformation and upgrading of the pig industry.

For the midstream circulation link, one is to focus on strengthening and improving the logistics system. On the one hand, through scientific research methods, the logistics distribution route is optimized, and modern distribution equipment is adopted to ensure the efficient circulation of products. On the other hand, the timely delivery of products has been realized by opening green channels for product transportation and building temporary storage centers during the epidemic prevention and control period. The second is to focus on strengthening the research of live pig circulation and processing technology, and strengthen the application of cold chain logistics and canned pork processing technologies in the circulation link to ensure product quality and improve the efficiency of circulation and transportation. The third is to focus on strengthening the supervision and management of pig slaughter. On the one hand, it is necessary to strengthen the infrastructure construction of pig slaughter, improve and optimize the equipment supply, and build a corporate environmental pollution management system. On the other hand, it is necessary to strengthen the quality control of pig slaughter products, and strictly control the quality of pig products entering the consumer market.

For the downstream consumption link, one is to focus on strengthening the supply of pork products and meat supply of other livestock products. In the past two years, both the slaughter and the stock of live pigs have been significantly reduced. The government should ensure the balance of meat supply and demand, and be wary of consumers overly relying on other livestock products. The second is to focus on strengthening price market supervision. Efforts will be made to strengthen price supervision, stabilize prices, and protect the interests of consumers while guiding the masses' good expectations. The third is to focus on strengthening the prevention and control of the pneumonia epidemic. The government authorities should step up efforts to prevent and control the epidemic, effectively control the domestic epidemic, and strictly prohibit the importation of the epidemic. If the epidemic can be effectively controlled for a long time, it will be possible to realize the restoration of household consumption, the restoration of social production capacity, and the return of macroeconomic growth to long-term growth.

Finally, after the writing of this paper, I have learned a lot and accumulated a lot of experience, but due to the lack of talent and ability, the model construction 
is relatively simple, many problems still need to be further thought and research.

\section{Conflicts of Interest}

The authors declare no conflicts of interest regarding the publication of this paper.

\section{References}

Ding, C. Z., Zheng, Y., \& Xiao, H. F. (2019). Analysis of Market Status of Broiler Industry under Avian Flu Crisis-Based on Internet Big Data and MS-VAR Model. Agricultural Resources and Regionalization in China, 40, 92-100.

Li, J., \& Jin, H. (2020). Influence of COVID-19 Epidemic on the Development of China's Mutton Sheep Industry. Chinese Journal of Animal Science, 56, 116-119.

Sui, X. C., \& Geng, X. H. (2019). Analysis on the Influence Mechanism of Exogenous Shocks on Egg Price Fluctuation-Based on the Empirical Analysis of VAR Model. Journal of Agricultural and Forestry Economics and Management, 18, 776-784.

Wu, P. R., Wang, G. X., \& Lang, Y. (2019). Influences of Epidemics on Price Fluctuation of Hogs-Analysis Based on VAR Model. Prices Monthly, 5, 1-6.

Xu, Y. M., \& Gao, Y. M. (2017). The Construction and Application of CPI Public Opinion Index Based on Internet Big Data-Taking Baidu Index as an Example. Quantitative and Technical Economics Research, 34, 94-112.

Yu, L. R., Li, X. Y., Wang, L. B., \& Zheng, H. (2009). Assessment of the Economic Impact of Avian Influenza on Poultry Farmers-Analysis Based on Panel Data of Two Periods. Chinese Rural Economy, No. 7, 12-19+30.

Zhang, X. C., \& Zhang, L. X. (2011). Study on the Impact of Emergent Events on Agricultural Product Price and Regulation Mechanism-Take China's Broiler Industry as an Example. Economist, No. 1, 22-24+26. 